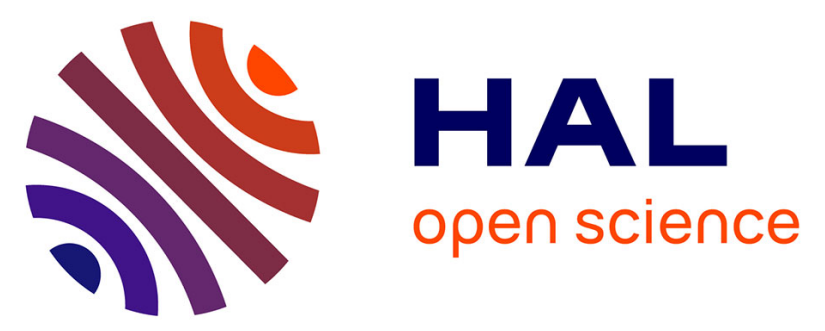

\title{
Zirconium-Catalyzed Synthesis of Alkenylaminoboranes: From a Reliable Preparation of Alkenylboronates to a Direct Stereodivergent Access to Alkenyl Bromides
} Mélodie Birepinte, Virginie Liautard, Laurent Chabaud, Mathieu Pucheault

\section{- To cite this version:}

Mélodie Birepinte, Virginie Liautard, Laurent Chabaud, Mathieu Pucheault. Zirconium-Catalyzed Synthesis of Alkenylaminoboranes: From a Reliable Preparation of Alkenylboronates to a Direct Stereodivergent Access to Alkenyl Bromides. Organic Letters, 2020, 22 (7), pp.2838-2843. 10.1021/acs.orglett.0c00908 . hal-02988440

\author{
HAL Id: hal-02988440 \\ https://hal.science/hal-02988440
}

Submitted on 19 Nov 2020

HAL is a multi-disciplinary open access archive for the deposit and dissemination of scientific research documents, whether they are published or not. The documents may come from teaching and research institutions in France or abroad, or from public or private research centers.
L'archive ouverte pluridisciplinaire $\mathbf{H A L}$, est destinée au dépôt et à la diffusion de documents scientifiques de niveau recherche, publiés ou non, émanant des établissements d'enseignement et de recherche français ou étrangers, des laboratoires publics ou privés. 


\title{
Zirconium-catalyzed synthesis of alkenylaminoboranes: from a reliable preparation of alkenylboronates to a direct stereo- divergent access to alkenylbromides.
}

\author{
Mélodie Birepinte, Virginie Liautard, Laurent Chabaud, Mathieu Pucheault*. \\ Institut des Sciences Moléculaires, UMR 5255, CNRS, Université de Bordeaux, 351 Cours de la libération, 33405 Talence.
}

Supporting Information Placeholder

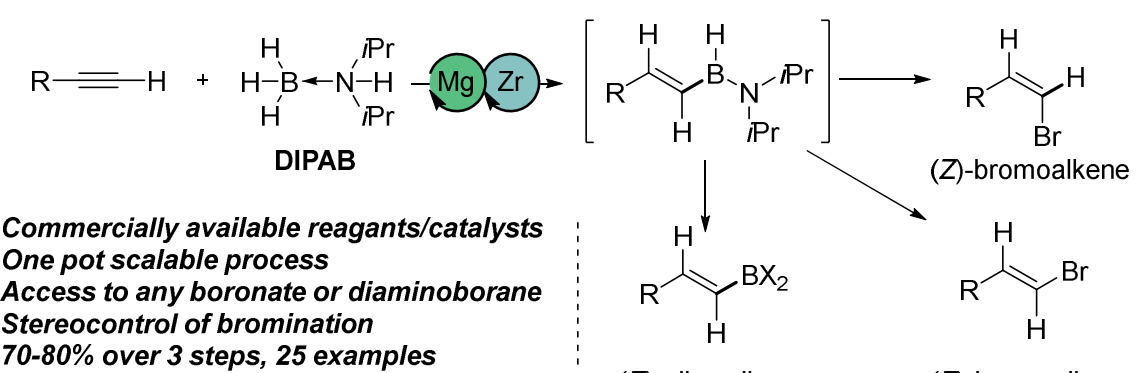

(E)-alkenylborane $\quad(E)$-bromoalkene

\begin{abstract}
A simple procedure has been optimized for the preparation of alkenylaminoborane from alkynes using diisopropylaminoborane and $\mathrm{HZrCp}_{2} \mathrm{Cl}$. Coupled with a magnesium catalyzed dehydrogenation, it allowed for the use air and moisture stable diisopropylamine.. This synthesis has been extended to a one-pot sequence leading directly to bromoalkenes with controlled stereochemistry. As such it provides an easy, scalable, cheap process to access alkenylboronates and both $(E)$-and $(Z)$-bromoalkenes from commercially available alkynes.
\end{abstract}

Alkenylboron derivatives are versatile building blocks ${ }^{1}$ traditionally used in Suzuki-Miyaura ${ }^{2}$ or Chan-Lam-Evans crosscoupling reactions. Recently, they have been elegantly used in metal-free halide mediated carbon-carbon bond formation. ${ }^{3}$ Similarly to most arylboron derivatives, alkenylboronates can be obtained by the addition of the corresponding Grignard or lithiated compounds to trialkoxyboranes or other boron centered electrophiles. However, the difficult preparation of vinylmetal and the low stability of the carbon-boron bond as borate usually lead to significantly lower yields than for the corresponding aromatic derivatives. Alternatively, transition metal catalyzed borylation of alkenylhalides or triflates is more efficient but somehow limited by the accessibility of starting materials, prepared in one or two steps from commercially available reagents. The reaction scope could nonetheless be widened by using dehydrogenative coupling of alkenes with boranes, which is often easier on styrenyl derivatives. Hence alkyne hydroboration remains the most reliable, high yielding and robust access to alkenylboranes. ${ }^{4}$ Over the last 50 years, many boranes have been used in this reaction, mostly 9-BBN, (ipc) ${ }_{2} \mathrm{BH}, \mathrm{Cy}_{2} \mathrm{BH}$, pinacolborane and catecholborane. ${ }^{5}$ Depending on substrates, the reaction can be sluggish and unselective, which led to the development of catalysts based on transition metal complexes of $\mathrm{Rh}^{6-8}, \mathrm{Ir}^{9,10}, \mathrm{Ru}^{11-13}, \mathrm{Co}^{14-16}, \mathrm{Al}^{17,18}$ $\mathrm{Fe}^{19-22}, \mathrm{Cu}^{23}, 24, \mathrm{Mg}^{25}, 26$ or $\mathrm{Zr}$ (Scheme 1-1). ${ }^{27}$ The resulting product function solely depends on the hydroboration reagent nature and often requires a tricky selective postfunctionalization to be used in the next synthetic steps.

Scheme 1: Relevant precedent examples in literature

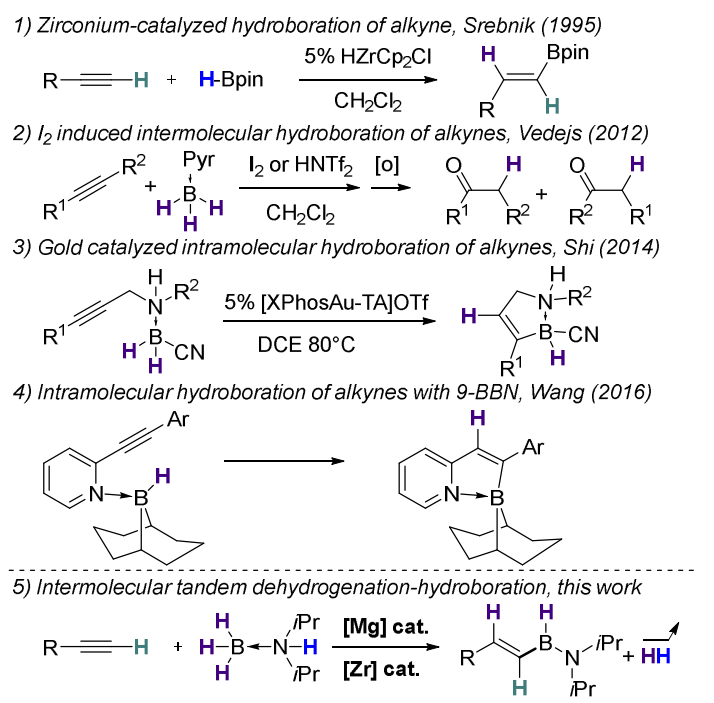

Aminoorganoboranes, on the other hand, are likely to be easily transformed in most common boronic acid derivatives 
using simple workup procedures and represent a more versatile synthon family. ${ }^{28,29}$ Access to these compounds has widely been described. ${ }^{28,}$ 30-36 For alkenyl analogs, only palladiumcatalyzed borylation of vinyltriflates and vinyl halides ${ }^{37}$ has been reported. Indeed, diisopropylaminoborane is unreactive in direct hydroboration of alkenes or alkynes, due to its poor Lewis acidity. This reagent is isoelectronic from diisopropylethene and one of the few aminoborane that exists under monomeric form in solution. ${ }^{38}$ So far, hydroboration of alkyne using aminoborane has only been described with $40 \%$ yield using unstable pyrroloborane. ${ }^{39}$ Amine borane complexes and alkynes can react intramolecularly (Scheme 1-4) (0) $^{40}$ using gold catalysts (Scheme 1-3) $)^{41}$ or using borenium intermediates ${ }^{42}$ generated with stoichiometric $\mathrm{I}_{2}$ or $\mathrm{HNTf}_{2}$ (Scheme 1-2). ${ }^{43} \mathrm{In}$ most cases, using organometallic catalysis with the alkyne/amine borane combination usually leads to hydrogen release, which is directly used in the semihydrogenation of the alkyne. ${ }^{44,45}$ As zirconocenes have been shown to dehydrogenate amine borane complexes leading to poly(aminoborane) or poly(iminoborane), ${ }^{46}$ an extra challenge was determining conditions under which the alkyne would react faster with zirconium hydride than the borane.

Scheme 2: Proposed catalytic cycles
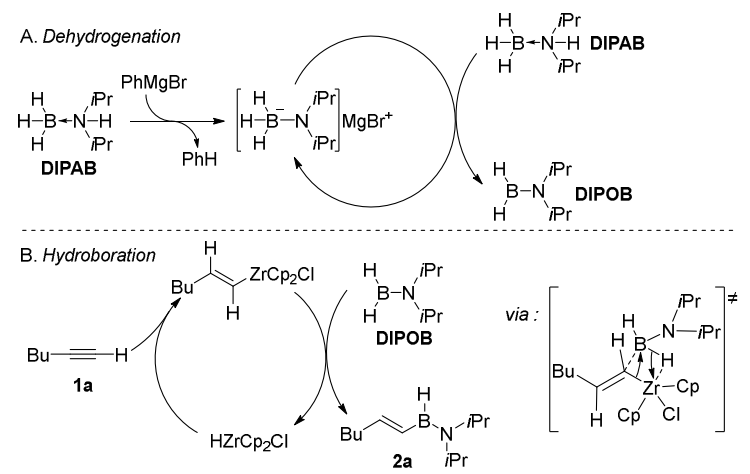

Mechanistically, we hypothesized that hydrozirconation of alkyne followed by reaction with disopropylaminoborane (DIPOB) would lead to alkenylaminoborohydride via $\sigma$-bond metathesis or intermolecular addition followed by direct hydride transfer (Scheme 2B). The addition of organozirconium reagents has been found to proceed only on chloroboranes only using Pd and $\mathrm{Ni}$ complexes ${ }^{47-50}$. In this reaction despite the high Lewis acidity of the chloroborane, no direct addition of organozirconium was observed. ${ }^{47}$ However, initial tests showed that vinylzirconium was reacting quite efficiently on DIPOB and the resulting compound was a mixture of the vinylaminoborane and Schwartz reagent. The putative intermediate alkenylaminoborohydride was not observed strengthening the $\sigma$-bond metathesis pathway and the zirconium hydride was regenerated completely. . As a result, it triggered the possibility of a catalytic version of the reaction, assuming the reaction conditions would be compatible with the hydrozirconation of alkyne. Indeed using 1.1eq of DIPOB and $12 \mathrm{~mol} \%$ of $\mathrm{ZrCp} \mathrm{p}_{2} \mathrm{HCl}$ the hydroboration of hexyne proceeded at $70^{\circ} \mathrm{C}$ with $100 \%$ conversion in MTBE (Scheme 3a). The reaction was also quite efficient in THF and MTBE (Supp. Info Table 1 entries 1-3), as the reaction was complete after 16h. In MTBE, either the reaction time or the catalyst loading could be re- duced without a significant loss in conversion and yield (Supp. Info Table 1, Entry 6-13).

One of the downsides of DIPOB is related to its relative instability toward air and moisture requiring distillation prior use. These limitations could be bypassed by inducing in situ dehydrogenation of the corresponding diisopropylamineborane complex (DIPAB). Direct reaction with DIPAB was unsuccessful (Scheme 3b). However, as described previously, ${ }^{28}$ $\mathrm{DIPAB}$ dehydrogenation could be performed at room temperature using as little as $5 \mathrm{~mol} \% \mathrm{PhMgBr}$, among other $\mathrm{Mg}$ complexes (Scheme 2A). ${ }^{51-53} \mathrm{We}$, therefore, attempted to sequentially add $\mathrm{PhMgBr}$ and after 5 minutes, Schwartz reagent (Scheme3c). Solvent and catalyst loading variation were performed (Supp. Info Table 2). The quantity of Schwartz reagent should be greater than the one required for dehydrogenation. Hence if $5 \%$ of $\mathrm{PhMgBr}$ is used, 10 to $12 \%$ of $\mathrm{HZrCp} \mathrm{Cl}_{2} \mathrm{Cl}$ would insured reproducible results and product was isolated in 92\% yield.. Noticeably, amine borane complexes have been known to participate in transition metal-catalyzed reaction with multiple carbon-carbon bonds, but usually as hydrogen sources, leading to alkanes, ${ }^{54,55}$ not hydroboration reagents.

Scheme 3: Hydroboration using various borane sources

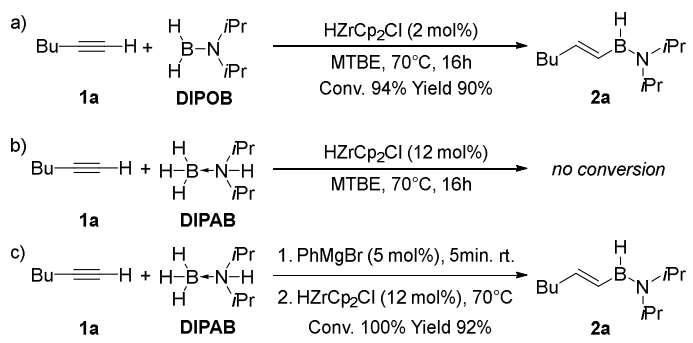

If the reaction could be run using in situ dehydrogenation followed by the hydroboration itself, remaining Grignard has led during the scoping study to side-reactions and generally lower yields than those obtained with pure DIPOB. The study was therefore pursued using the aminoborane, keeping in mind that careful optimization of stoichiometry between $\mathrm{PhMgBr}$ and $\mathrm{HZrCp}_{2} \mathrm{Cl}$ could prevent side reaction to occur on some trickier substrates. An example will be given of this in the last part of this study with the in situbromination.

Scheme 4: Synthesis of alkenylaminoboranes

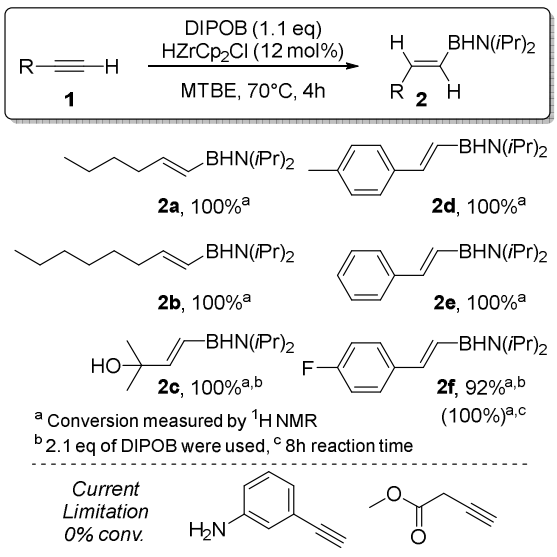

After having checked that conversions were complete on most simple substrates (Scheme 4), we found out that the 
reaction worked equally well on 1-methylbutynol provided that 2 equivalents of DIPOB were used. Only aniline and methylester were found to be incompatible with the reaction conditions (Scheme 4). As some substrates were less reactive, a $4 \mathrm{~h}$ reaction time was kept as a standard. The versatility of the reaction was proven using classical workup procedure on few substrates in order to obtain the various boron derivatives (29 examples, Scheme 5) which could easily be accessed from alkenylaminoboranes: 1,5-diazaborolanes using 1,8diaminonaphthalene (Scheme 5A), and boronic esters using pinacol (Scheme 5B)or neopentyl glycol (Scheme 5C). In the case of Bdan, the purification over silica gel led to yield diminution. However, the alkenyldiazaborolane were still isolated in 53-93\% yield depending on the starting material. The reaction tolerates chloride (3h), substituted phenyl rings (3d, 3e, Scheme 5: Synthesis of alkenyldiazaborolanes 3f), silylated alcohols (3j). Ene-yne are fairly reactive affording borylated diene in $53 \%$ yield. In general substitution by an alkyl chain led to the best isolated yields (3a, 3b, 3g, 3h, 3j, 3k, 31). For pinacolboronate and neopentylglycol boronates, yields are generally higher (63-98\%) due to the lower propensity of protodeborylation during purification. Group tolerance is very similar, and the reaction is efficient in the presence of alcohols (4c, 5n, 5o), chlorides (4h, 5h), bromides (4n), phthalimide $(\mathbf{4 l}, \mathbf{5 l})$, silylether $(\mathbf{4 j}, \mathbf{5 j})$, silane $(\mathbf{4 m})$. As witnessed by the reaction on enyne $(\mathbf{4 i}, \mathbf{5 i})$, the hydroboration of carbon-carbon double bonds was not observed, even on nonconjugated substrates bearing multiple functionalities such as lynestrenol (4p). To date, mestranol despite displayed no potentially problematic functional group failed to react even using $20 \mathrm{~mol} \%$ catalyst at a higher temperature.

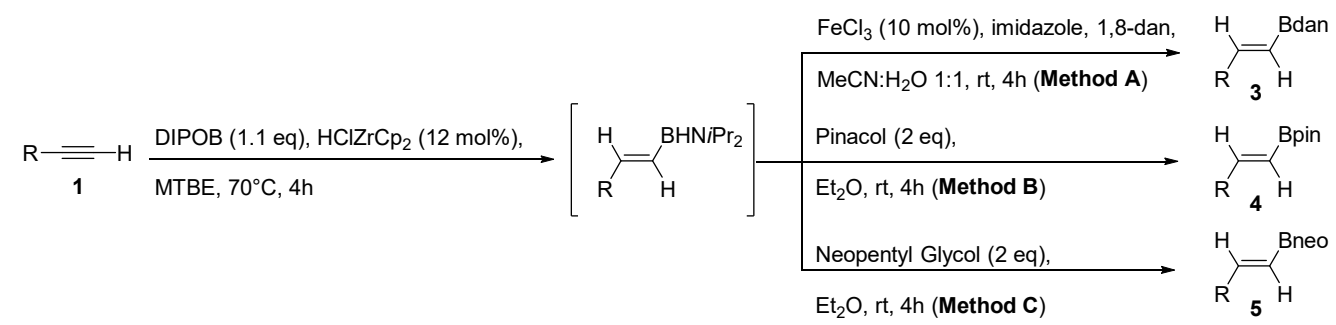

Method A :

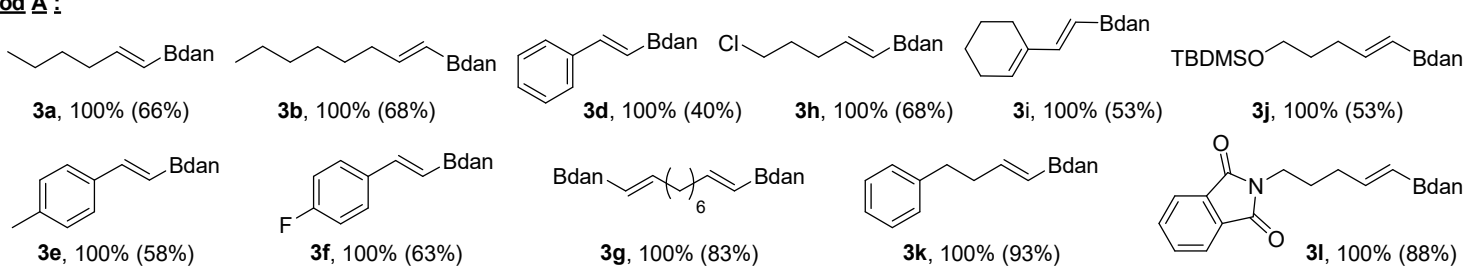

\section{Method $\underline{B}$ :}

$n \mathrm{Bu} / \mathrm{Bpin}$

4a, $100 \%(93 \%)$

$n \mathrm{Hex}>\mathrm{Bpin}$

HO

\begin{abstract}
4b, $100 \%(96 \%)$
\end{abstract}
Bpin

$\mathrm{Ph} 、{ }_{\text {Bpin }}$

4d, $100 \%(97 \%)$
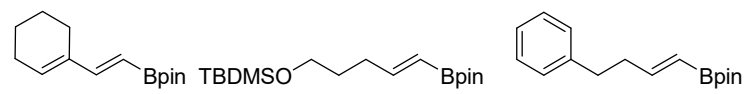

$4 \mathbf{j}, 100 \%(92 \%)$

4k, $100 \%(98 \%)$

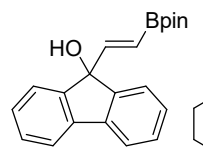

TBDMS $>_{\text {Bpin }}$

$4 \mathrm{~m}, 100 \%(95 \%)$

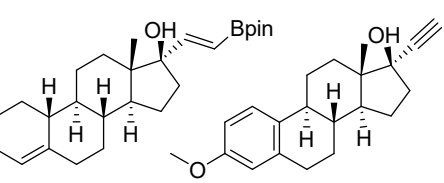

4 I, $100 \%(88 \%)$
4 p, $100 \%(88 \%)$
Mestranol : $0 \%$

\section{Method $\underline{\mathrm{C}}$ :}

$\sim$ Bneo

5a, $100 \%(93 \%)$

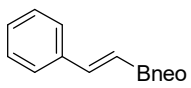

Cl Bneo TBDMSO $\sim(B$ Bneo

5h, $100 \%$ (94\%)

5j, $100 \%(96 \%)$
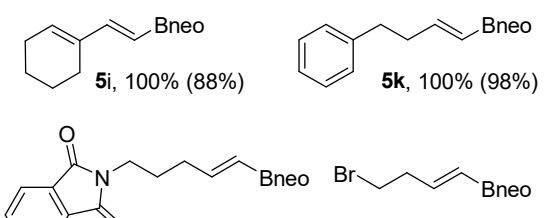

5I, $100 \%(88 \%) \quad 5 n, 100 \%(98 \%)$
As previously mentioned, the reaction can be performed directly on air-stable amine borane complexes. 4-phenylbut-1yne was converted to the corresponding boronate in $96 \%$ yield on a $10 \mathrm{mmol}$ scale over the course of 4 reactions performed in a single pot (dehydrogenation using $\mathrm{PhMgBr}, \mathrm{Zr}$-catalyzed hydroboration, dehydrocoupling with $\mathrm{MeOH}$ and transesterification with the neopentylglycol or pinacol, scheme 6). On substituted propargyl alcohol (fluorenol and lynestrenol), the reaction works equally well affording the neopentylglycol boronates in $92 \%$ and $88 \%$ yield respectively.

Scheme 6: Reaction extension using in situ dehydrogenation

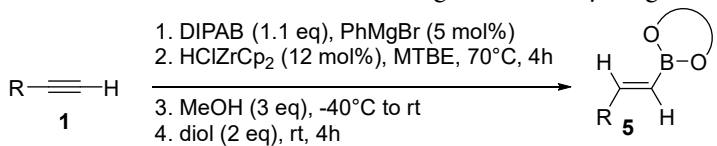<smiles>BrC=CCCCc1ccccc1</smiles>

$\mathbf{5 k}, 100 \%(96 \%)$ $10 \mathrm{mmol}$ scale 2.29g

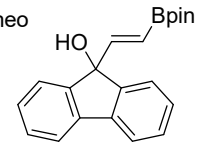

4o, $100 \%$ (92\%)

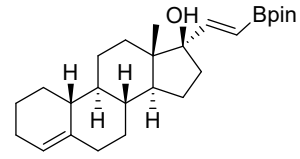

4p, $100 \%(88 \%)$ 
The tandem dehydrogenation-hydroboration process was then extended to the formation of vinylbromide. These compounds are highly useful building blocks for cross-coupling reactions, and classical preparation methods usually afford configurationally more stable $(E)$-bromoolefins ${ }^{56}$. After optimization (See Supp. Info), we found that a methanolysis followed by a treatment with $\mathrm{CuBr}_{2}$ in a THF: $\mathrm{H}_{2} \mathrm{O}$ mixture was leading to the (E)-bromoolefin (Scheme $7 \mathrm{~A}$ ), whereas a direct addition of $\mathrm{Br}_{2}$, followed by a basic methanolysis using $\mathrm{MeONa}$ was providing mostly the $(Z)$-bromoolefin (Scheme 7B). The reaction could also be performed starting from DIPOB and the alkyne, but the in situ dehydrogenation usually provided better results by avaoiding the manipulation of sensitive aminoborane. With this stereodivergent method in hand, we prepared 19 different bromoolefins with a very good control of stereochemistry in the case of $(E)$-isomers ( $E: Z$ ratio > 94:6) (Scheme 7A). Similarly, when the resulting olefin is not bond to an $\mathrm{sp} 2$ carbon, the $(Z)$-isomers were isolated with Scheme 7: Stereodivergent access to bromoolefins almost perfect control of the stereochemistry ( $Z: E$ ratio > 94:6). For dec-1,9-diyne, both (E)-6g and (Z)-6g isomers were isolated in good yields and good stereoselectivity, $56 \%$ (E:Z 98:2) and 84\% (Z:E 96:4) respectively. In most cases alkyl-derived bromoolefin were obtained in good yields $((\boldsymbol{E})$ 6b and (Z)-6b; ((E)-6h and (Z)-6h); (E)-6k and (Z)-6k). The reaction is mostly limited by the product volatility as witnessed by the impracticality of obtaining a pure sample of $(Z)$-bromobutene and $(Z)$-bromohexene $(Z)$-6a despite a complete conversion and a $>80 \%$ NMR yield. The problem was similar to TBDMS-acetylene products $((\boldsymbol{E})-\mathbf{6 m}$ and $(Z)$ 6m), for which the selectivity was close to perfect $(>99: 1)$ but yields were deceiving low ( $41 \%$ and $46 \%$ respectively). For enyne products $((\boldsymbol{E})-\mathbf{6 i}$ and $(\boldsymbol{Z})-\mathbf{6} \mathbf{i})$, as well as styrenylbromides $(((\boldsymbol{E})-\mathbf{6 d}$ and $(\boldsymbol{Z}) \mathbf{- 6 \mathbf { d }} ;((\boldsymbol{E})-\mathbf{6 e}$ and $(\boldsymbol{Z})-\mathbf{6 e})$, products were isolated in good yields, but selectively was displaced in favor of the $(E)$-olefin due to further isomerization into the most stable isomer under the reaction conditions.

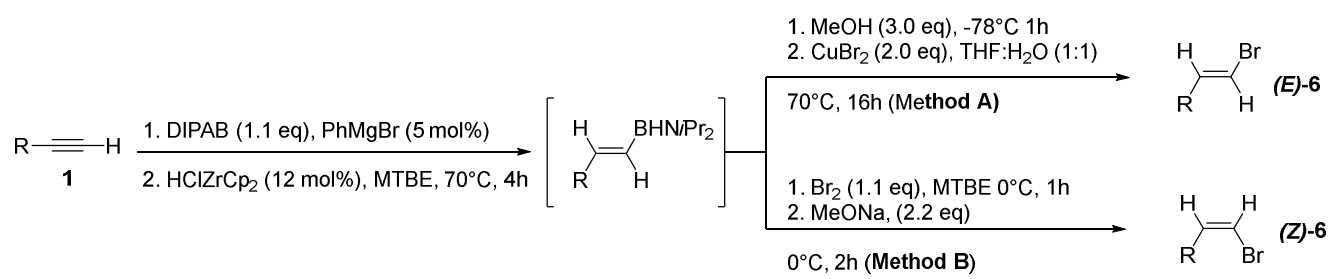

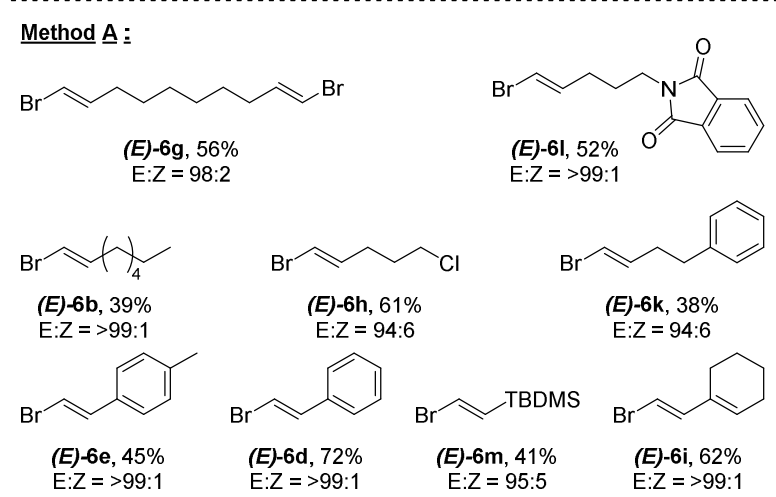

Overall, diisopropylaminoborane, which is unreactive towards alkene and alkyne, was found to be a good hydroboration reagent when combined with $\mathrm{HClZrCp}_{2}$ used as a catalyst. The reaction was optimized on various substrates, including alcohols and halides which could be incompatible with classical hydroboration conditions. Depending on the workup conditions, the resulting alkenylaminoboranes could be transformed into the corresponding borinic acid derivatives (diaminoborane or boronates), but also into bromoolefins by displacement of the boron atom by bromine. The last reaction could, at will, provide both bromoalkene stereoisomers without requiring isolation the boron intermediate. Finally, as DIPAB is air and moisture stable, this hydroboration reagent could advantageously replace more reactive boranes which are often quite sensitive.

\section{ASSOCIATED CONTENT}

\section{Supporting Information}

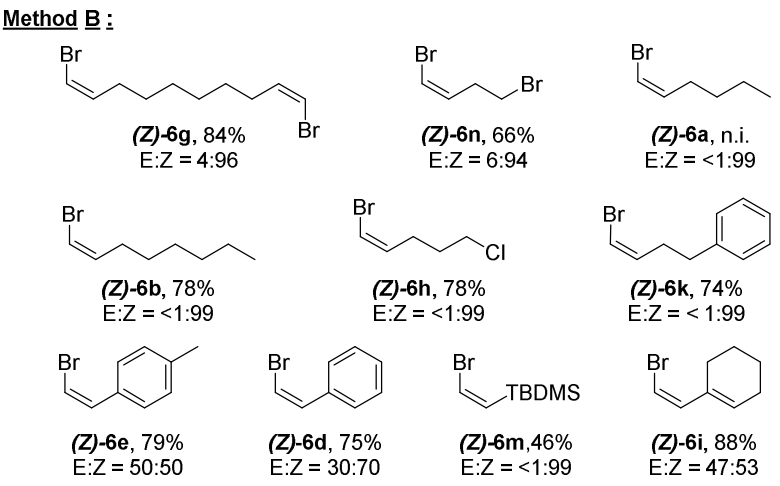

The Supporting Information is available free of charge on the ACS Publications website. Experimental Procedure, ${ }^{1} \mathrm{H},{ }^{11} \mathrm{~B},{ }^{13} \mathrm{C}$ NMR, HRMS of compounds (PDF)

\section{AUTHOR INFORMATION}

\section{Corresponding Author}

* Dr. Mathieu Pucheault Institute of Molecular Science, CNRS, Université de Bordeaux, 351 cours de la libération, 33405 Talence cedex E-mail: mathieu.pucheault@u-bordeaux.fr.

\section{Author Contributions}

The manuscript was written through contributions of all authors. / All authors have given approval to the final version of the manuscript.

\section{ACKNOWLEDGMENT}

This work was funded by the Université de Bordeaux and the CNRS. M.B. thanks the Ministère de l'Education Nationale, de 
l'Enseignement Supérieur et de la Recherche for a fellowship. V.L. thanks AST Innovations for funding.

\section{REFERENCES}

1. Vaultier, M.; Pucheault, M., Science of Synthesis 2012, 6, Houben Weyl - Thieme Verlag VCH.

2. Miyaura, N., Organoboron Compounds. In CrossCoupling Reactions, Miyaura, N., Ed. Springer Berlin / Heidelberg: 2002; Vol. 219, pp 11-59.

3. Leonori, D.; Aggarwal, V. K., Angew. Chem. Int. Ed. 2015, $54(4), 1082-1096$

4. Zaidlewicz, M.; Wolan, A.; Budny, M., 8.24 Hydrometallation of CC and CC Bonds. Group 3. In Comprehensive Organic Synthesis II (Second Edition), Knochel, P., Ed. Elsevier: Amsterdam, 2014; pp 877-963.

5. Barbeyron, R.; Benedetti, E.; Cossy, J.; Vasseur, J.-J.; Arseniyadis, S.; Smietana, M., Tetrahedron 2014, 70 (45), 84318452 .

6. $\quad$ Pereira, S.; Srebnik, M., Tetrahedron Lett. 1996, 37 (19), 3283-3286.

7. Ohmura, T.; Yamamoto, Y.; Miyaura, N., J. Am. Chem. Soc. 2000, $122(20)$, 4990-4991.

8. Carreras, L.; Serrano-Torné, M.; van Leeuwen, P. W. N. M.; Vidal-Ferran, A., Chem. Sci. 2018, 9 (15), 3644-3648.

9. Knorr, J. R.; Merola, J. S., Organometallics 1990, 9 (12), 3008-3010.

10. Iwadate, N.; Suginome, M., Org. Lett. 2009, 11 (9), 1899 1902.

11. Burgess, K.; Jaspars, M., Organometallics 1993, 12 (10), 4197-4200.

12. Sundararaju, B.; Fürstner, A., Angew. Chem. Int. Ed. 2013 52 (52), 14050-14054.

13. Gunanathan, C.; Hölscher, M.; Pan, F.; Leitner, W., J. Am. Chem. Soc. 2012, 134 (35), 14349-14352.

14. Obligacion, J. V.; Neely, J. M.; Yazdani, A. N.; Pappas, I.; Chirik, P. J., J. Am. Chem. Soc. 2015, 137 (18), 5855-5858.

15. Guo, J.; Cheng, B.; Shen, X.; Lu, Z., J. Am. Chem. Soc 2017, 139 (43), 15316-15319.

16. Ben-Daat, H.; Rock, C. L.; Flores, M.; Groy, T. L.; Bowman, A. C.; Trovitch, R. J., Chem. Commun. 2017, 53 (53), 7333-7336.

17. Yang, Z.; Zhong, M.; Ma, X.; Nijesh, K.; De, S.; Parameswaran, P.; Roesky, H. W., J. Am. Chem. Soc. 2016, 138 (8), 2548-2551.

18. Bismuto, A.; Thomas, S. P.; Cowley, M. J., Angew. Chem. Int. Ed. 2016, 55(49), 15356-15359.

19. Espinal-Viguri, M.; Woof, C. R.; Webster, R. L., Chem. Eur.J. 2016, 22 (33), 11605-11608.

20. Nakajima, K.; Kato, T.; Nishibayashi, Y., Org. Lett. 2017, $19(16), 4323-4326$.

21. Gorgas, N.; Alves, L. G.; Stöger, B.; Martins, A. M.; Veiros, L. F.; Kirchner, K., J. Am. Chem. Soc. 2017, 139 (24), 8130-8133.

22. Zhang, L.; Peng, D.; Leng, X.; Huang, Z., Angew. Chem. Int. Ed. 2013, 52 (13), 3676-3680.

23. Semba, K.; Fujihara, T.; Terao, J.; Tsuji, Y., Chem. Eur. J. 2012, 18 (14), 4179-4184.

24. Bidal, Y. D.; Lazreg, F.; Cazin, C. S. J., ACS Catalysis 2014, 4(5), 1564-1569.

25. Li, J.; Luo, M.; Sheng, X.; Hua, H.; Yao, W.; Pullarkat, S. A.; Xu, L.; Ma, M., Org. Chem. Front. 2018, 5 (24), 3538-3547.

26. Magre, M.; Maity, B.; Falconnet, A.; Cavallo, L.; Rueping, M., Angew. Chem. Int. Ed. 2019, 58 (21), 7025-7029.

27. Pereira, S.; Srebnik, M., Organometallics 1995, 14 (7),
28. Marciasini, L. D.; Richard, J.; Cacciuttolo, B.; Sartori, G.; Birepinte, M.; Chabaud, L.; Pinet, S.; Pucheault, M., Tetrahedron 2019, 75(2), 164-171.

29. Wood, J. L.; Marciasini, L.; Vaultier, M.; Pucheault, M., Synlett 2014, 25, 551-555.

30. Marciasini, L. D.; Vaultier, M.; Pucheault, M., Tetrahedron Lett. 2014, 55 (10), 1702-1705.

31. Guerrand, H. D. S.; Marciasini, L. D.; Jousseaume, M.; Vaultier, M.; Pucheault, M., Chem. Eur. J. 2014, 20 (19), 5573-5579.

32. Guerrand, H. D. S.; Marciasini, L. D.; Gendrineau, T.; Pascu, O.; Marre, S.; Pinet, S.; Vaultier, M.; Aymonier, C.; Pucheault, M., Tetrahedron 2014, 70(36), 6156-6161.

33. Pascu, O.; Marciasini, L.; Marre, S.; Vaultier, M.; Pucheault, M.; Aymonier, C., Nanoscale 2013, 5(24), 12425 - 12431.

34. Marciasini, L. D.; Richy, N.; Vaultier, M.; Pucheault, M., Adv. Synth. Catal. 2013, 355 (6), 1083-1088.

35. Gendrineau, T.; Marre, S.; Vaultier, M.; Pucheault, M.; Aymonier, C., Angew. Chem. Int. Ed. 2012, 51 (34), 8525-8528.

36. Euzenat, L.; Horhant, D.; Ribourdouille, Y.; Duriez, C.; Alcaraz, G.; Vaultier, M., Chem. Commun. 2003, (18), 2280-2281.

37. Euzenat, L.; Horhant, D.; Brielles, C.; Alcaraz, G.; Vaultier, M., J. Organomet. Chem. 2005, 690 (11), 2721-2724.

38. Robertson, A. P. M.; Leitao, E. M.; Jurca, T.; Haddow, M. F.; Helten, H.; Lloyd-Jones, G. C.; Manners, I., J. Am. Chem. Soc. 2013, 135 (34), 12670-12683.

39. Pasumansky, L.; Haddenham, D.; Clary, J. W.; Fisher, G. B.; Goralski, C. T.; Singaram, B., J. Org. Chem. 2008, 73 (5), 18981905 .

40. Yuan, K.; Suzuki, N.; Mellerup, S. K.; Wang, X.; Yamaguchi, S.; Wang, S., Org. Lett. 2016, 18 (4), 720-723.

41. Wang, Q.; Motika, S. E.; Akhmedov, N. G.; Petersen, J. L.; Shi, X., Angew. Chem. Int. Ed. 2014, 53 (21), 5418-5422.

42. De Vries, T. S.; Prokofjevs, A.; Vedejs, E., Chem. Rev. 2012, $112(7), 4246-4282$.

43. Clay, J. M.; Vedejs, E., J. Am. Chem. Soc. 2005, 127(16), 5766-5767.

44. Vasilikogiannaki, E.; Titilas, I.; Vassilikogiannakis, G.; Stratakis, M., Chem. Commun. 2015, 51 (12), 2384-2387.

45. Fu, S.; Chen, N.-Y.; Liu, X.; Shao, Z.; Luo, S.-P.; Liu, Q. J. Am. Chem. Soc. 2016, 138 (27), 8588-8594.

46. Helten, H.; Dutta, B.; Vance, J. R.; Sloan, M. E.; Haddow, M. F.; Sproules, S.; Collison, D.; Whittell, G. R.; Lloyd-Jones, G. C.; Manners, I., Angew. Chem. Int. Ed. 2013, 52, 437-440.

47. Daini, M.; Suginome, M., Chem. Commun. 2008, (41), 5224-5226.

48. Daini, M.; Suginome, M., J. Am. Chem. Soc. 2011, 133, 4758-4761.

49. Daini, M.; Yamamoto, A.; Suginome, M., J. Am. Chem. Soc. 2008, 130, 2918-2919.

50. Daini, M.; Yamamoto, A.; Suginome, M., Asian J. Org. Chem. 2013, 2, 968-976.

51. Spielmann, J.; Bolte, M.; Harder, S., Chem. Commun. 2009, (45), 6934-6936.

52. Liptrot, D. J.; Hill, M. S.; Mahon, M. F.; MacDougall, D. J., Chem. Eur.J.2010, 16(28), 8508-8515.

53. Hill, M. S.; Hodgson, M.; Liptrot, D. J.; Mahon, M. F., Dalton Trans. 2011, 40(30), 7783-7790.

54. Sloan, M. E.; Staubitz, A.; Lee, K.; Manners, I., Eur.J. Org. Chem. 2011, 2011 (4), 672-675.

55. Revunova, K.; Nikonov, G. I., Dalton Trans. 2015, 44(3), 840-866.

56. Kabalka, G. W.; Mereddy, A. R., Organometallics 2004, 23 (19), 4519-4521. 